Article

\title{
Zinc Oxide Nanoparticles Obtained by Supercritical Antisolvent Precipitation for the Photocatalytic Degradation of Crystal Violet Dye
}

\author{
Paola Franco, Olga Sacco* $*$, Iolanda De Marco $\mathbb{D}^{\mathbb{B}}$ and Vincenzo Vaiano \\ Department of Industrial Engineering, University of Salerno, 84084 Fisciano, Italy; pfranco@unisa.it (P.F.); \\ idemarco@unisa.it (I.D.M.); vvaiano@unisa.it (V.V.) \\ * Correspondence: osacco@unisa.it; Tel.: +39-089-964006
}

Received: 20 March 2019; Accepted: 5 April 2019; Published: 9 April 2019

\begin{abstract}
In this work, the synthesis of zinc oxide $(\mathrm{ZnO})$ photocatalyst from thermal decomposition of zinc acetate ( $\mathrm{ZnAc}$ ) nanoparticles obtained by supercritical antisolvent (SAS) precipitation was investigated. The optimization of calcination conditions of the SAS ZnAc was carried out, studying the effect of temperature (in the range $300-600{ }^{\circ} \mathrm{C}$ ) on the production of $\mathrm{ZnO}$ nanoparticles. In particular, it was demonstrated that the organic residues in $\mathrm{ZnO}$ and its particle size, thus the specific surface area, strongly affect the photocatalytic performances. SAS micronization of ZnAc produces regular nanoparticles with a mean diameter of about $54.5 \pm 11.5 \mathrm{~nm}$, whereas unprocessed ZnAc is characterized by very large crystals. The experimental results evidenced that ZnAc prepared by SAS process calcined at $500^{\circ} \mathrm{C}$ showed a regular nanometric structure (mean diameter: $65.0 \pm 14.5 \mathrm{~nm}$ ) and was revealed to be the best choice for the photocatalytic removal of crystal violet dye (CV). In fact, the photocatalytic activity performances of $\mathrm{ZnO}$ nanoparticles prepared by this route were higher with respect to that of $\mathrm{ZnO}$ from unprocessed $\mathrm{ZnAc}$ calcined at $500{ }^{\circ} \mathrm{C}$ (which is characterized by irregular tetrapods with mean size $181.1 \pm 65.5 \mathrm{~nm}$ ). The optimized photocatalyst was able to assure the complete $\mathrm{CV}$ decolorization in $60 \mathrm{~min}$ of $\mathrm{UV}$ irradiation time and a mineralization degree higher than $90 \%$ after 120 min of treatment time.
\end{abstract}

Keywords: $\mathrm{ZnO}$; supercritical antisolvent precipitation; zinc acetate; crystal violet dye; photocatalysis; water and wastewater treatment

\section{Introduction}

Nowadays, organic dyes are considered the main pollutants in the wastewater coming from a large number of industries, including textile, paint, paper, ink, rubber, and plastic manufacturing activities. It is estimated that approximately $15-20 \%$ of these dyes are lost during synthesis or processing and they are released in the industrial wastewaters [1-3]. Organic dyes are generally present in wastewater in concentrations ranging from 5 to $1500 \mathrm{mg} / \mathrm{L}$, causing serious problems for the environment and the health of living organisms, such as carcinogenic and mutagenic effects, due to their toxicity [4].

Conventional methods used to remove dyes from the wastewater, like biological processes, flocculation, coagulation, filtration, and precipitation, have some drawbacks, mainly due to a low removal efficiency [5,6], since dyes are stable to the light and the oxidizing agent [7]. On the contrary, a promising alternative is the heterogeneous photocatalysis $[8,9]$, which is an advanced oxidation technology that allows removal of a great variety of organic pollutants with a very efficient degradation rate [10-12].

Up to now, different semiconductor materials have been employed to treat the colored wastewater though photocatalytic methods, especially titanium dioxide $\left(\mathrm{TiO}_{2}\right)$, which still has several limits as well 
as most of the photocatalysts studied, i.e., the deactivation caused by ions scavengers in the solution and a low degradation kinetic in the presence of a high content of dyes in aqueous samples [13]. These disadvantages can be overcome by using zinc oxide $(\mathrm{ZnO})$, which recently has received a considerable interest in the photocatalytic field because of its non-toxicity, low cost, high catalytic efficiency, wide band gap energy (3.37 eV at room temperature), and great potential to adsorb UV light irradiation [14]. In some literature works, it was also demonstrated that $\mathrm{ZnO}$ is more effective than $\mathrm{TiO}_{2}$ to remove pollutants in the wastewater [15], including organic dyes [16].

For all these reasons, many studies focused on the improvement of $\mathrm{ZnO}$ photocatalytic performance, for example by the deposition of noble metals on $\mathrm{ZnO}$ surface, such as $\mathrm{Au}, \mathrm{Pt}, \mathrm{Pd}$, and $\mathrm{Ag}$ [17-20], or the doping of $\mathrm{ZnO}[13,21,22]$.

Another promising approach to enhance the photocatalytic performance is the particle size reduction of $\mathrm{ZnO}$, or generally speaking, of semiconductors, because it is well known that the physical and chemical properties are strongly influenced by the morphology and particle size [23].

In this perspective, the method employed to produce $\mathrm{ZnO}$ nanoparticles plays an important role in the control of morphology and size. Traditional synthesis methods, such as precipitation, coprecipitation, colloidal methods, sol-gel processing, water-oil microemulsions method, hydrothermal synthesis, solvothermal, sonochemical, as well as polyol method [24], make it difficult to obtain well-separated nanoparticles with a narrow particle size distribution (PSD). Moreover, a massive use of organic and inorganic solvents, like nitrates, ammonia, diethylene glycol [25], ethylene glycol [26], 2-methoxyethanol with monoethanolamine [27], and hydroxides, are often required to obtain $\mathrm{ZnO}$ nanopowders [28-31].

An innovative environmentally friendly route to produce high-activity catalyst nanoparticles in a controlled manner is the supercritical anti solvent (SAS) precipitation [32-34], which is the most effective micronization technique based on the use of supercritical carbon dioxide $\left(\mathrm{scCO}_{2}\right)$ as an antisolvent. In particular, the SAS process is based on the following main prerequisites: $\mathrm{scCO}_{2}$ has to be completely miscible with the liquid solvent used during the process, whereas the solute to be micronized has to be soluble in the selected solvent and insoluble in the mixture solvent $/ \mathrm{scCO}_{2}[35,36]$. The very fast diffusion of $\mathrm{scCO}_{2}$ into the liquid solvent produces the supersaturation of the solute leading to its precipitation in form of nanoparticles. This phenomenon, in addition to the quasi-zero surface tension of $\mathrm{scCO}_{2}$, allows one to obtain particles of smaller size with a narrow PSD with respect to the traditional micronization techniques. Another advantage of the application of the SAS technique to produce catalysts is the decreased use of toxic and polluting solvents, which lowers the environmental impact of long-term catalyst preparation. In addition to this, conventional methods of catalysts synthesis often involve obtaining not completely pure catalysts due to the organic residues.

It is worthwhile to note that, as far as we know, only two papers were focused on the preparation by SAS process of $\mathrm{TiO}_{2}$ to be used as photocatalyst $[37,38]$. Therefore, the effectiveness of SAS precipitation for photocatalytic applications is still unexplored.

For this reason, for the first time, in this work the use of zinc acetate nanoparticles produced by SAS technique as precursor of $\mathrm{ZnO}$ photocatalyst was attempted. The optimization of the calcination conditions and photocatalytic tests for the removal of an organic dye from aqueous solutions were carried out. In detail, crystal violet (CV) was chosen as the model dye, being one of the main widespread dying agents and because of its related toxicity $[39,40]$.

\section{Results}

\subsection{Characterization of ZnAc Nanoparticles by SAS Technique}

Zinc acetate $(\mathrm{ZnAc})$ nanoparticles were produced by the SAS technique according to the results obtained in a previous work [41] focused on the micronization of ZnAc. In detail, selecting dimethylsulfoxide (DMSO) as liquid solvent, SAS experiments were performed using a flow rate of the liquid solution and of $\mathrm{CO}_{2}$ equal to $1 \mathrm{~mL} \times \mathrm{min}^{-1}$ and $30 \mathrm{~g} \times \mathrm{min}^{-1}$, respectively. Moreover, the 
operating temperature and pressure were set at $40{ }^{\circ} \mathrm{C}$ and $150 \mathrm{bar}$, whereas a concentration of $\mathrm{ZnAc}$ in DMSO equal to $15 \mathrm{mg} \times \mathrm{mL}^{-1}$ was chosen. DMSO is one of the best solvents used for SAS process, as shown by SAS literature; in particular, in this specific case, the use of DMSO allowed us to respect the basic hypotheses of the supercritical antisolvent precipitation: ZnAc powder is recovered in the precipitator at the end of the SAS experiment and not extracted by $\mathrm{scCO}_{2}$.

The field emission scanning electron microscope (FESEM) analyses revealed that unprocessed ZnAc is characterized by very large crystals, whose surface is shown in Figure 1a; whereas, SAS processed $\mathrm{ZnAc}$ is formed by nanoparticles (Figure 1b) with a mean diameter of about $54.5 \pm 11.5 \mathrm{~nm}$.

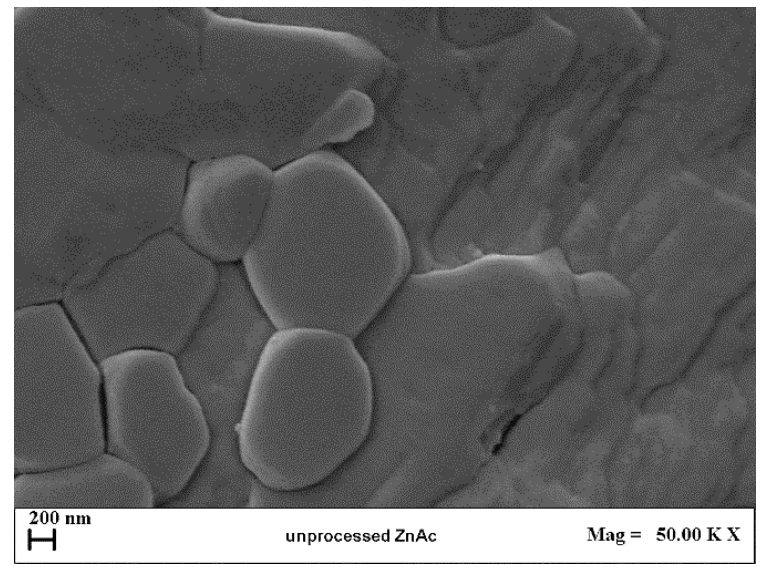

(a)

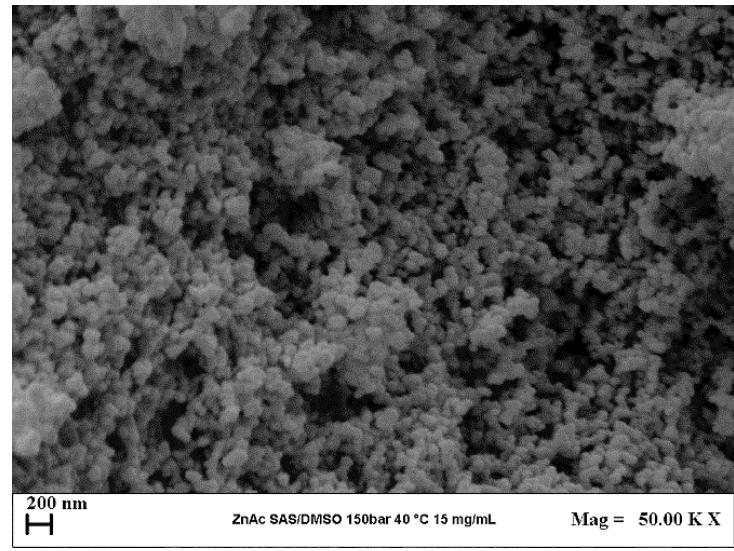

(b)

Figure 1. Field emission scanning electron microscope (FESEM) images of unprocessed zinc acetate (ZnAc) (a) and supercritical antisolvent (SAS) ZnAc nanoparticles (b) precipitated from dimethylsulfoxide DMSO at $150 \mathrm{bar}, 40^{\circ} \mathrm{C}$, and $15 \mathrm{mg} \times \mathrm{mL}^{-1}$.

Fourier transform infrared spectroscopy (FT-IR) analyses were also performed for unprocessed and SAS processed ZnAc. The obtained results are reported in Figure 2. The comparison of the corresponding spectra demonstrated that some changes occurred in the powders after the SAS process, probably due to a carbonation process that occurred in the presence of $\mathrm{CO}_{2}$ [41]. However, this modification was not significant to produce the $\mathrm{ZnO}$ photocatalyst, since a thermal decomposition step was necessary after the $\mathrm{ZnAc}$ micronization process.

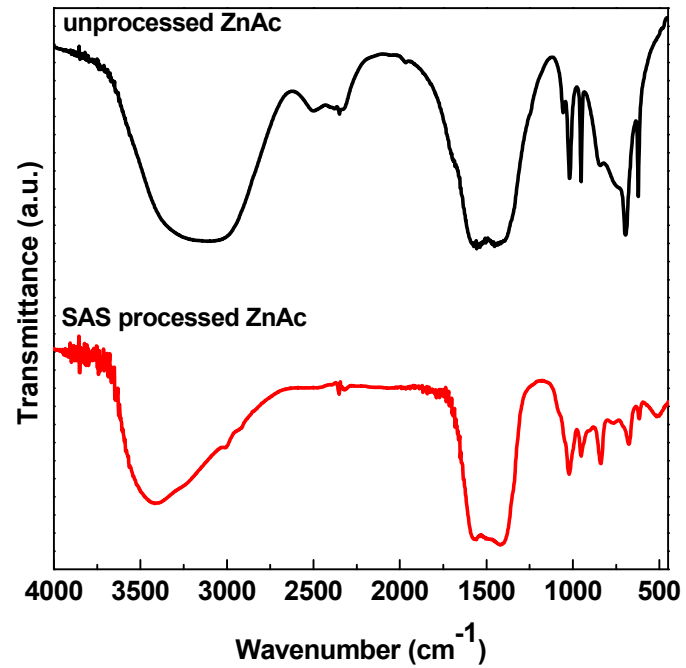

Figure 2. Fourier transform infrared (FT-IR) spectra of unprocessed and supercritical antisolvent (SAS) processed zinc acetate (ZnAc). 
Moreover, specific surface area (SSA) was measured using the Brunauer, Emmett, and Teller (BET) equation for unprocessed and SAS processed ZnAc. In particular, an increase of the SSA after the SAS process from $3 \mathrm{~m}^{2} \times \mathrm{g}^{-1}$ to $20 \mathrm{~m}^{2} \times \mathrm{g}^{-1}$ was observed. As can be seen from the FESEM results (Figure 1), the increase of SSA could be attributed to the lower value of ZnAC particle size obtained by the SAS technique.

\subsection{Characterization of $\mathrm{ZnO}$ Photocatalysts}

With the aim of obtaining zinc oxide, ZnAc nanoparticles produced by SAS were calcined at different temperatures $\left(300,400,500\right.$, and $\left.600{ }^{\circ} \mathrm{C}\right)$ to investigate the effect of different calcination conditions, which can strongly influence the characteristics of the samples [42]. Moreover, in order to do a comparison, unprocessed $\mathrm{ZnAc}$ was also calcined at $500{ }^{\circ} \mathrm{C}$ to evaluate the potential of SAS process in the preparation of a $\mathrm{ZnO}$ photocatalyst.

A summary of the samples calcined at different temperatures is reported in Table 1 with the indication of the calcination temperature $\left(T_{c}\right)$, morphology, mean diameter (m.d.), and standard deviation (s.d.) of particles, in addition to SSA and band-gap energy values.

Table 1. Summary of the experimental results $\left(\mathrm{T}_{\mathrm{c}}=\right.$ calcination temperature; $\mathrm{NP}=$ nanoparticles; $\mathrm{m} . \mathrm{d}$. = mean diameter; s.d. = standard deviation).

\begin{tabular}{cccccc}
\hline Sample & $\begin{array}{c}\mathbf{T}_{\mathbf{c}} \\
\left({ }^{\circ} \mathbf{C}\right)\end{array}$ & Morphology & $\begin{array}{c}\text { m.d. } \pm \text { s.d. } \\
(\mathbf{n m})\end{array}$ & $\begin{array}{c}\text { BET Surface Area } \\
\left(\mathbf{m}^{\mathbf{2}} \times \mathbf{g}^{-\mathbf{1}}\right)\end{array}$ & $\begin{array}{c}\text { Band-Gap } \\
\text { Energy }(\mathbf{e V})\end{array}$ \\
\hline \multirow{3}{*}{ ZnOSAS } & 300 & NP & $38.6 \pm 7.1$ & 33 & 3.12 \\
& 400 & NP & $57.3 \pm 10.5$ & 15 & 3.07 \\
& 500 & NP & $65.0 \pm 14.5$ & 12 & 3.10 \\
\hline $\begin{array}{c}\text { ZnO from } \\
\text { unprocessed ZnAc }\end{array}$ & 600 & NP & $156.7 \pm 30.1$ & 6 & 3.15 \\
\hline
\end{tabular}

FESEM images of the various $\mathrm{ZnO}$ samples are reported in Figure 3. It can be observed that $\mathrm{ZnO}$ obtained from unprocessed $\mathrm{ZnAc}$ was characterized by irregular tetrapods (Figure 3d). On the contrary, $\mathrm{ZnO}$ produced from SAS processed $\mathrm{ZnAc}$ showed in any case a regular nanometric structure (Figure 3a-d) with a mean diameter that increased by increasing the calcination temperature, probably due to the sintering phenomena. In particular, slightly coalescing nanoparticles were observed when $\mathrm{ZnO}$ was obtained with a calcination temperature of $600^{\circ} \mathrm{C}$. 


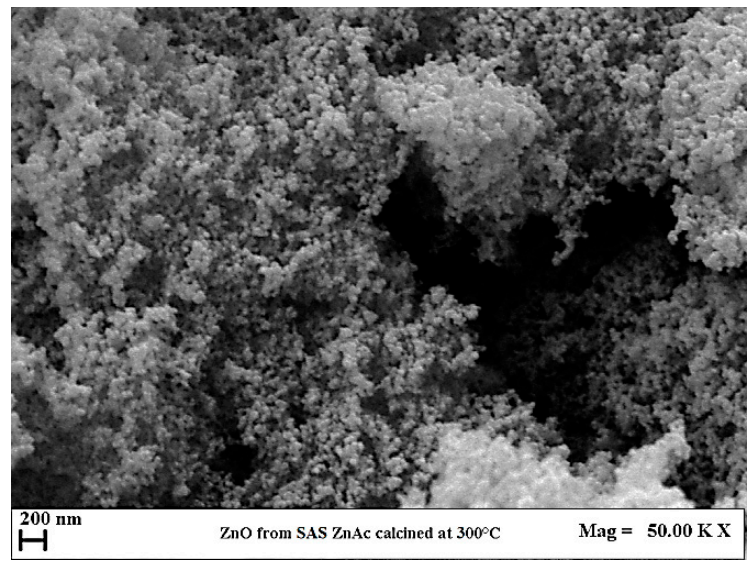

(a)

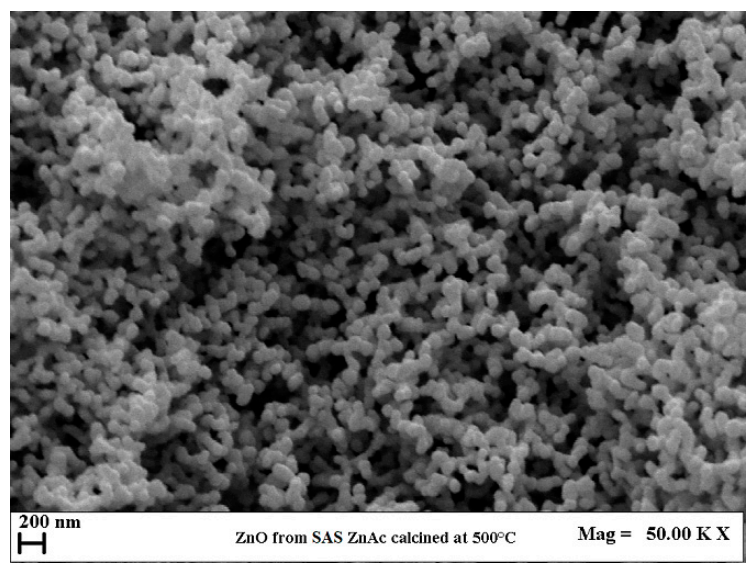

(c)

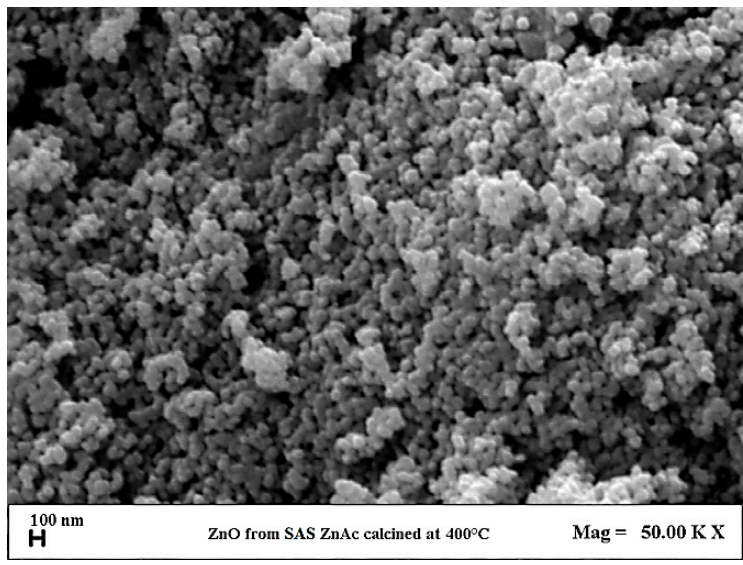

(b)

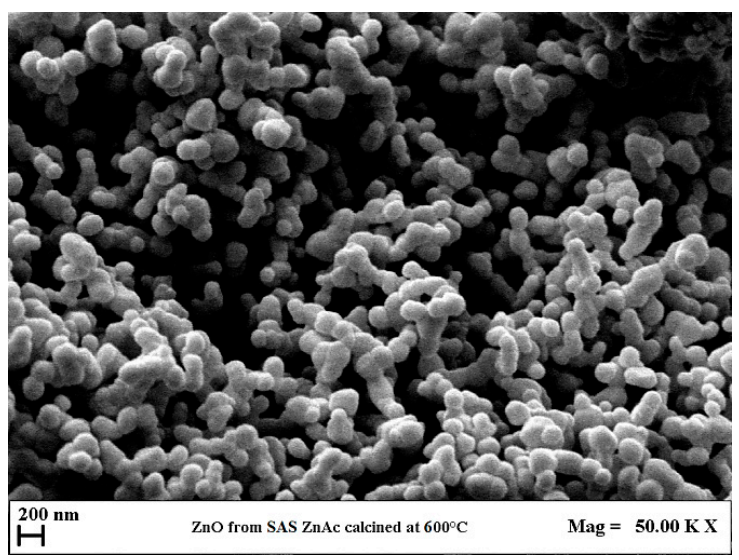

(d)

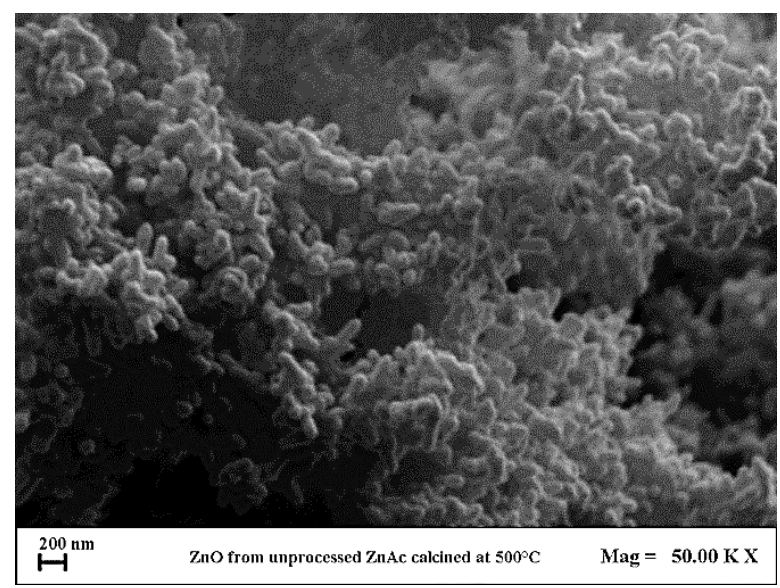

(e)

Figure 3. Field emission scanning electron microscope (FESEM) images of zinc oxide (ZnO) nanoparticles obtained from supercritical antisolvent (SAS) processed zinc acetate (ZnAc) calcined at $300{ }^{\circ} \mathrm{C}(\mathbf{a})$, $400{ }^{\circ} \mathrm{C}(\mathbf{b}), 500{ }^{\circ} \mathrm{C}(\mathbf{c})$, and $600{ }^{\circ} \mathrm{C}(\mathbf{d})$; and $\mathrm{ZnO}$ produced from unprocessed $\mathrm{ZnAc}(\mathbf{e})$.

The SSA of all the prepared $\mathrm{ZnO}$ samples is also reported in Table 1. From the BET measurement, it is evident that the $\mathrm{ZnO}$ sample obtained from the calcination of $\mathrm{ZnAC}$ micronized by the SAS technique at $500{ }^{\circ} \mathrm{C}$ (ZnOsas500) showed a higher specific surface area $\left(12 \mathrm{~m}^{2} \times \mathrm{g}^{-1}\right)$ than the one obtained from the unprocessed $\mathrm{ZnAc}$ sample obtained with the same calcination temperature (ZnOac500), being equal to $5 \mathrm{~m}^{2} \times \mathrm{g}^{-1}$. It is important to underline that generally a larger surface area offers more active 
adsorption sites that are catalytically active, which means that a higher surface area could result in a higher photocatalytic activity [43].

In order to identify the characteristic groups of zinc oxide, $\mathrm{ZnO}$ samples were analyzed by FT-IR spectroscopy as shown in Figure 4. According to the literature [44], in any case, FT-IR spectra of ZnO samples exhibited a peak at about $3450 \mathrm{~cm}^{-1}$ assigned to the vibrations of $\mathrm{O}-\mathrm{H}$ and the bands attributed to the stretching vibrations of $\mathrm{Zn}-\mathrm{OH}$ and $\mathrm{Zn}-\mathrm{O}$ at about $900 \mathrm{~cm}^{-1}$ and $450 \mathrm{~cm}^{-1}$, respectively. The only difference was the presence of the strong peak related to the symmetric valency band of $\mathrm{C}-\mathrm{H}$ at about $3000 \mathrm{~cm}^{-1}$ in the spectrum of $\mathrm{ZnO}$ from unprocessed $\mathrm{ZnAc}$ (ZnOac500). This peak was less evident in $\mathrm{ZnO}$ prepared from SAS ZnAc calcined at 300 and $400{ }^{\circ} \mathrm{C}$ and it seemed to completely disappear when SAS ZnAc nanoparticles were calcined at 500 and $600^{\circ} \mathrm{C}$ (Figure $4 \mathrm{~b}$ ), probably as a result of a better removal of the organic parts due to the higher specific surface area. This achievement confirmed that the SAS micronization allowed production of very pure $\mathrm{ZnO}$ catalysts even at lower calcination temperatures. The Raman spectra of all $\mathrm{ZnO}$ samples in the range $200-2000 \mathrm{~cm}^{-1}$ are shown in Figure 5 . All prepared $\mathrm{ZnO}$ samples, in the range $200-1200 \mathrm{~cm}^{-1}$ showed six main bands at 275, 333, 380.9, 436, 581 , and $1150 \mathrm{~cm}^{-1}$, related to the zinc oxide [45]. The main band observed at $436 \mathrm{~cm}^{-1}$ corresponded to the non-polar optical phonons $\mathrm{E}_{2}$ (high) mode of $\mathrm{ZnO}$ in wurtzite $\mathrm{ZnO}$ form [46]. The features located at 333 and $380.9 \mathrm{~cm}^{-1}$ corresponded to the multi-phonon scattering process $\mathrm{E}_{2 \mathrm{H}}-\mathrm{E}_{2 \mathrm{~L}}$ and $\mathrm{A}_{1}$ (TO) phonons of $\mathrm{ZnO}$ crystal, respectively [13], while the peak at $581 \mathrm{~cm}^{-1}$ corresponded to $\mathrm{E}_{1}$ (LO) mode. The low intense bands in the range $1025-1200 \mathrm{~cm}^{-1}$ were attributed to the optical overtones and associated with the second-order Raman active modes of $\mathrm{ZnO}$ [47]. In the range 1200-2000 $\mathrm{cm}^{-1}$ the sample ZnOac500 showed strong Raman signals associated to the bending vibration of water at $1650 \mathrm{~cm}^{-1}$, to the symmetric and antisymmetric C-O vibrations as well as to two $\mathrm{CH}_{3}$ deformations (Figure 5a) [47]. It is important to underline that these bands almost disappeared when SAS ZnAc nanoparticles were calcined at $500{ }^{\circ} \mathrm{C}$ (ZnOsas500).
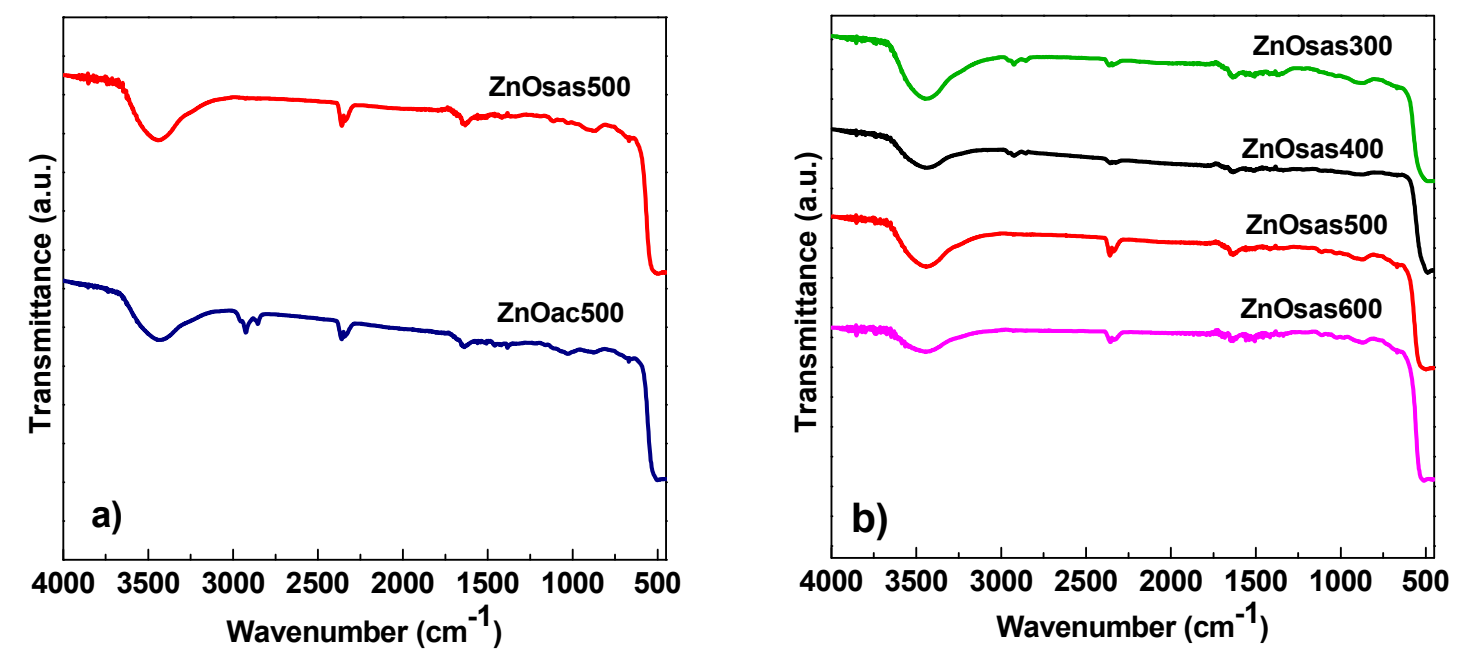

Figure 4. Fourier transform infrared (FT-IR) spectra of (a) zinc oxide $(\mathrm{ZnO})$ from supercritical antisolvent (SAS) zinc acetate ( $\mathrm{ZnAc}$ ) nanoparticles calcined at $500{ }^{\circ} \mathrm{C}$ and $\mathrm{ZnO}$ from unprocessed $\mathrm{ZnAc}$ calcined at $500{ }^{\circ} \mathrm{C}$; (b) $\mathrm{ZnO}$ from SAS ZnAc nanoparticles calcined at 300, 400, 500, and $600{ }^{\circ} \mathrm{C}$. 

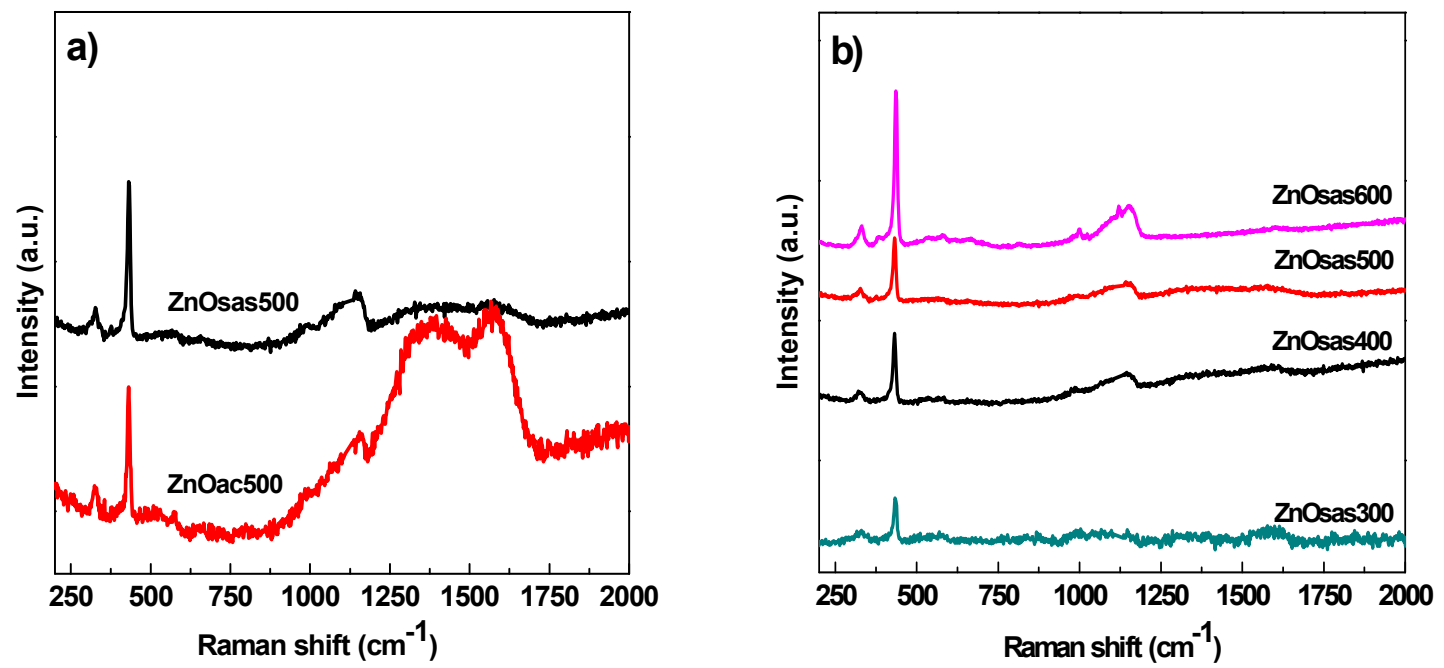

Figure 5. Raman shift of (a) zinc oxide ( $\mathrm{ZnO}$ ) from supercritical antisolvent (SAS) zinc acetate (ZnAc) nanoparticles calcined at $500{ }^{\circ} \mathrm{C}$ and $\mathrm{ZnO}$ from unprocessed $\mathrm{ZnAc}$ calcined at $500{ }^{\circ} \mathrm{C}$; (b) $\mathrm{ZnO}$ from SAS ZnAc nanoparticles calcined at 300, 400, 500, and $600{ }^{\circ} \mathrm{C}$.

The optical properties (Figure 6) and electronic band gap energies (Table 1) of $\mathrm{ZnO}$ samples were analyzed using UV-Vis DRS spectroscopy. The reflectance spectrum of the two ZnO samples calcined at the same temperature $\left(500{ }^{\circ} \mathrm{C}\right)$ exhibited a different trend (Figure 6a). In particular, the ZnOsas500 sample showed a decrease of the reflectance values from $440 \mathrm{~nm}$ while the absorption onset of ZnOac500 sample was lower and equal to $410 \mathrm{~nm}$. This red shift may be attributed to the increase of agglomeration size occurring in the samples [48-51]. In fact, as previously observed from the FESEM images, the ZnOac550 sample appeared as nano tetrapods with mean size almost equal to $181 \mathrm{~nm}$ while the sample ZnOsas500 had a regular nanometric structure with mean size almost equal to $65 \mathrm{~nm}$. Figure $6 \mathrm{~b}$ shows the effect of calcination temperature on the reflectance spectrum of $\mathrm{ZnO}$ samples. Additionally, in this case, the trend was in good agreement with the mean size particles as evidenced from FESEM analysis; the increase of particles size (from 35 to $156 \mathrm{~nm}$ ) due to the calcination temperature led to a little red shift of the absorption onset [51]. Based on the reflectance data, the optical band gap energy of the samples was measured by the extrapolation of the linear portion of the graph between the modified Kubelka-Munk function $(F(R) \times h \times v)^{2}$ versus the photon energy $(h \times$ $v$ ); the obtained values are reported in Table 1. The optical band gap values were about $3.17 \mathrm{eV}$ for ZnOac500 and $3.10 \mathrm{eV}$ for ZnOsas500, confirming that the optical band gap of $\mathrm{ZnO}$ could be tuned by using different synthesis techniques [52]. In addition, the calcination temperature slightly influenced the band gap value that was equal to $3.12 \mathrm{eV}$ (for ZnOsas300), $3.07 \mathrm{eV}$ (for ZnOsas400), $3.10 \mathrm{eV}$ (for $\mathrm{ZnOsas500)}$, and $3.15 \mathrm{eV}$ (for $\mathrm{ZnOsas600).} \mathrm{Despite} \mathrm{the} \mathrm{calcination} \mathrm{temperature} \mathrm{inducing} \mathrm{differences}$ in the $\mathrm{ZnO}$ crystallinity [43], in our case, it could be argued that the increase of particle size with the increase of calcination temperature possessed low impact in the crystalline structure of $\mathrm{ZnO}$ and therefore, the defects were likely quite similar [53]. This probably induced no significantly differences in the UV absorption edge and, as a consequence, the band gap energy values were similar for the samples calcined at different temperature [53]. 

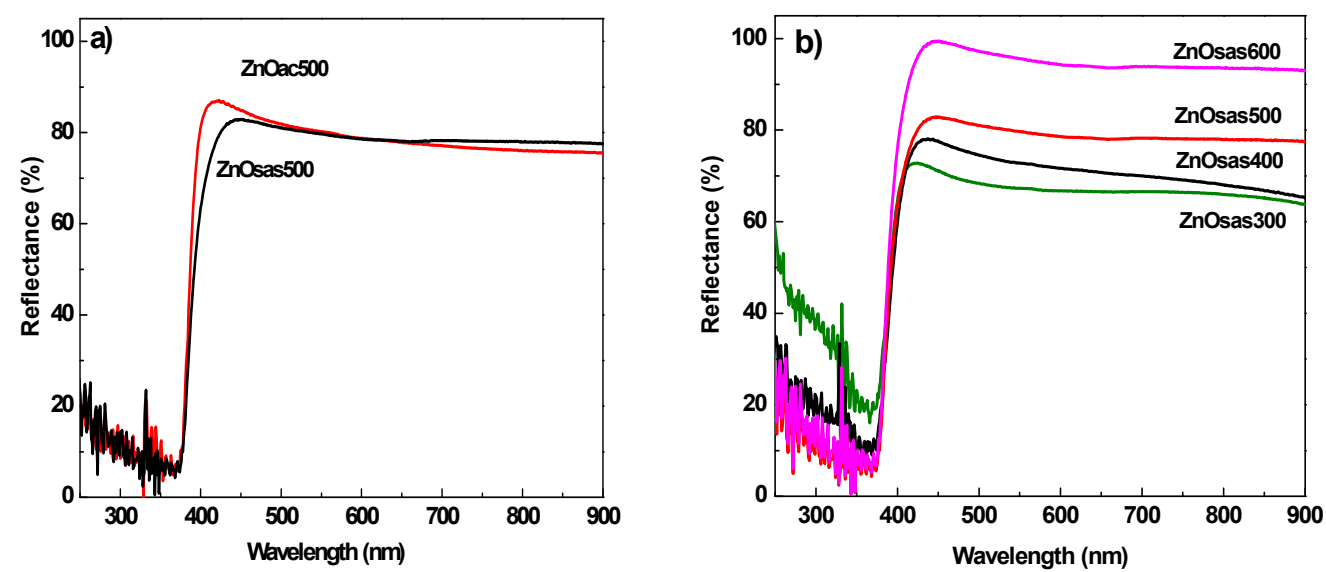

Figure 6. UV-Vis diffuse reflectance spectra of (a) zinc oxide $(\mathrm{ZnO})$ from supercritical antisolvent (SAS) zinc acetate $(\mathrm{ZnAc})$ nanoparticles calcined at $500{ }^{\circ} \mathrm{C}$ and $\mathrm{ZnO}$ from unprocessed $\mathrm{ZnAc}$ calcined at $500{ }^{\circ} \mathrm{C}$; (b) ZnO from SAS ZnAc nanoparticles calcined at 300, 400, 500, and $600{ }^{\circ} \mathrm{C}$.

\subsection{Photocatalytic Activity Results}

Figure 7 shows the photocatalytic results of $\mathrm{CV}$ degradation using the ZnOac500 and ZnOsas500 samples under UV irradiation.

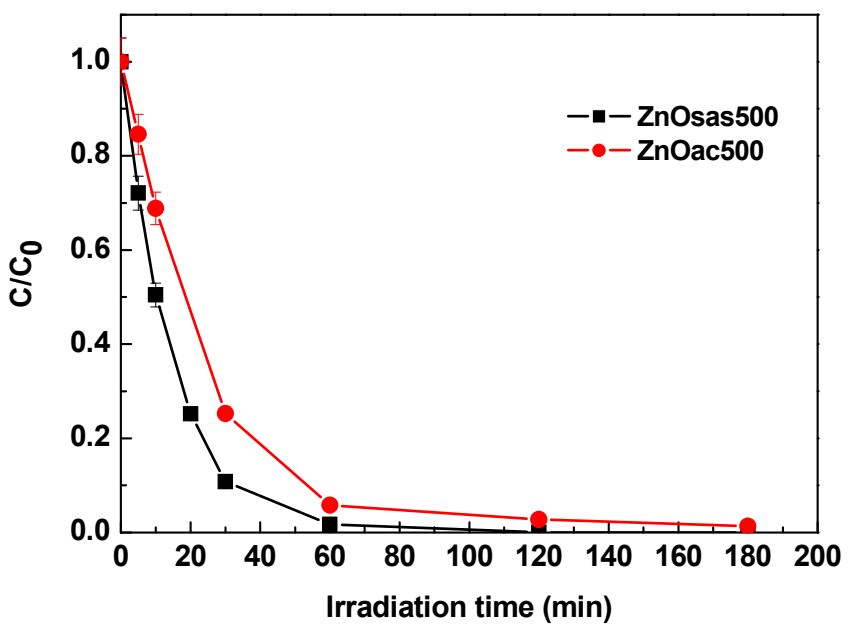

Figure 7. Photocatalytic decolorization of crystal violet (CV) using ZnOac500 and ZnOsas500 under UV irradiation.

At irradiation times lower than $60 \mathrm{~min}$, the $\mathrm{C} / \mathrm{C}_{0}$ values for $\mathrm{ZnOsas500}$ were always lower than the values observed for the $\mathrm{ZnOac500}$ sample. Therefore, the photocatalytic activity results evidenced that the best CV decolorization performances were achieved using the ZnOsas500 sample, leading to the almost total CV decolorization after $60 \mathrm{~min}$ of UV irradiation. It is worthwhile to note that, in the case of $\mathrm{ZnOac500} \mathrm{sample,} \mathrm{an} \mathrm{irradiation} \mathrm{time} \mathrm{noticeably} \mathrm{higher} \mathrm{(180} \mathrm{min}$ ) was necessary to reach the complete $\mathrm{CV}$ decolorization.

With the aim to analyze the influence of zinc acetate nanoparticles produced by SAS technique as precursor for $\mathrm{ZnO}$ particles, the photocatalytic activity data of ZnOac500 and ZnOsas500 were discussed considering the characterizations results. As pointed out above, the SAS technique is able to produce $\mathrm{ZnAc}$ nanoparticles having a surface area of $20 \mathrm{~m}^{2} \times \mathrm{g}^{-1}$, whereas unprocessed $\mathrm{ZnAc}$ is characterized by very large crystals, whose SSA is significantly lower, being equal to $3 \mathrm{~m}^{2} \times \mathrm{g}^{-1}$. These differences influenced the properties of $\mathrm{ZnO}$ obtained after the thermal treatment of SAS $\mathrm{ZnAc}$ and unprocessed ZnAc particles at $500{ }^{\circ} \mathrm{C}$. In particular, FESEM results showed that the ZnOsas500 sample had a lower particle size and a higher SSA with respect to ZnOac500, which also 
showed a morphology characterized by irregular tetrapods. These features could explain the superior photocatalytic performances of the ZnOsas500 sample. In fact, it has been reported that, in most cases, the enhancement of photocatalytic activity is linked to the increase in SSA values that occurs when the nanoparticles become smaller [54,55], leading also to the fast charge migration from bulk to the surface of the photocatalyst since ZnOsas500 particles are regular in structure (Figure 3) [56]. However, it must be taken into account that, as shown in the FT-IR and Raman spectra, ZnOac500 showed the presence of organic impurities that instead were totally absent for the ZnOsas500 sample. Since the CV degradation typically depends on the charge transfer process at photocatalyst interface, the presence of surface organic impurity may negatively affect the photocatalytic performances [57]. In particular, the organic impurities in contact with photocatalyst surface could act as radical scavengers, influencing the charge recombination process $[57,58]$ and hence worsening the photocatalytic activity of $\mathrm{ZnOac500}$ with respect to $\mathrm{ZnOsas500} \mathrm{photocatalyst.} \mathrm{It} \mathrm{is} \mathrm{worthwhile} \mathrm{to} \mathrm{note} \mathrm{that} \mathrm{the} \mathrm{photocatalytic}$ performances achieved with $\mathrm{ZnOsas500} \mathrm{photocatalyst} \mathrm{were} \mathrm{better} \mathrm{than} \mathrm{those} \mathrm{reported} \mathrm{in} \mathrm{some} \mathrm{research}$ papers dealing with the photocatalytic degradation of $\mathrm{CV}$ dye using $\mathrm{ZnO}$ nanoparticles under UV irradiation $[59,60]$. In particular, it was evidenced that the complete $\mathrm{CV}$ decolorization was achieved for irradiation times generally higher than $80 \mathrm{~min}$.

The effect of calcination temperature (Figure 8) on ZnAc micronized by the SAS technique was also investigated both in terms of CV decolorization (Figure 8a) and total organic carbon (TOC) removal (Figure 8b). Intentionally, TOC was analyzed together with the CV decolorization, since the rational pollutants abatement in aqueous matrices should involve also its complete mineralization rather than its transformation to other species, which could be more toxic than the initial molecule [61]. It is worthwhile to note that, within $60 \mathrm{~min}$ of UV irradiation, ZnOsas500 achieved total CV decolorization with a TOC removal equal to about $92 \%$ after $120 \mathrm{~min}$, showing, therefore, the best photocatalytic performance under UV light. Moreover, it was possible to observe that the photocatalytic activity of the calcined $\mathrm{ZnOsas}$ samples increased with the increase in the calcination temperature up to $500{ }^{\circ} \mathrm{C}$. Despite ZnOsas300 and ZnOsas400 being characterized by a higher SSA and lower particle size (Table 1) than $\mathrm{ZnOsas500,} \mathrm{the} \mathrm{lower} \mathrm{photocatalytic} \mathrm{activity} \mathrm{for} \mathrm{the} \mathrm{photocatalysts} \mathrm{calcined} \mathrm{at} 300$ and $400{ }^{\circ} \mathrm{C}$ could be ascribed to the presence of organic impurities (as observed from FT-IR spectra) that were instead absent in the sample calcined at $500{ }^{\circ} \mathrm{C}$. On the other hand, the decrease of the photocatalytic activity observed for the ZnOsas600 sample could be due to the decrease of SSA and the increase of particle size (Table 1) with respect to ZnOsas500. In summary, the photocatalytic results showed an optimum calcination temperature able to assure the best photocatalytic performances towards the $\mathrm{CV}$ removal from aqueous solutions (almost total CV decolorization after $60 \mathrm{~min}$ ).
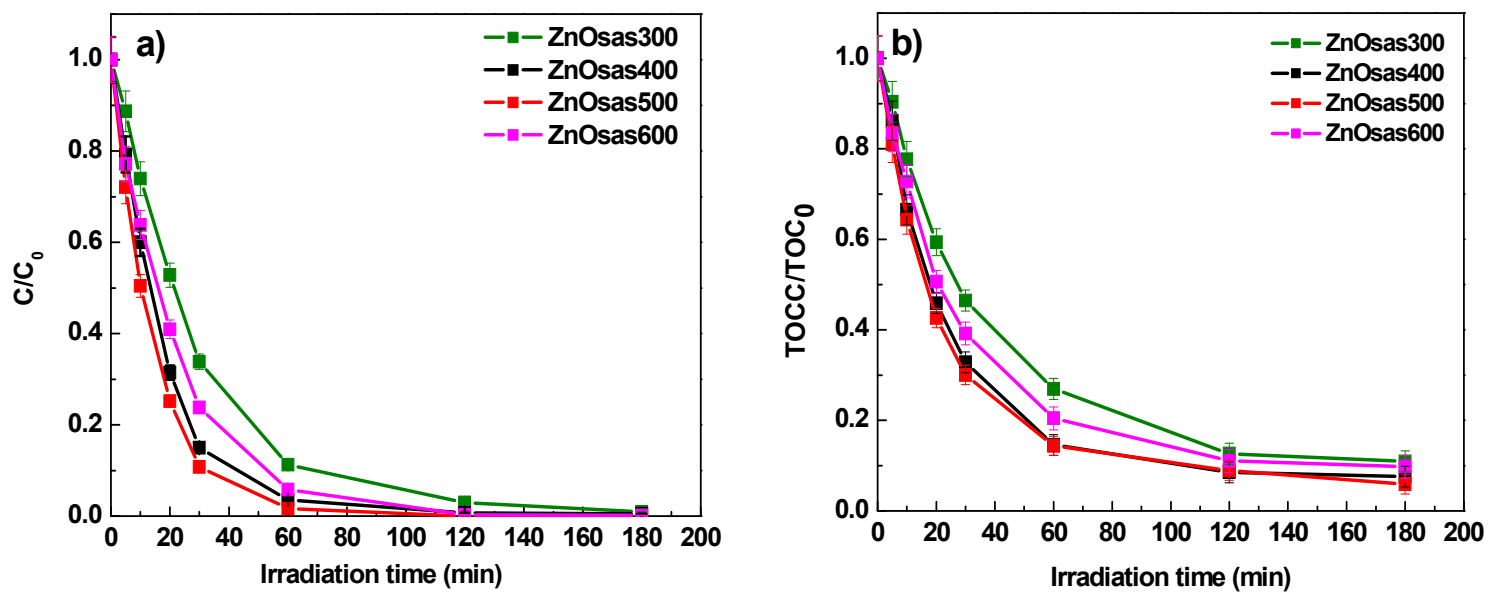

Figure 8. (a) Photocatalytic decolorization of crystal violet (CV) and (b) Total Organic Carbon (TOC) behavior under UV light using zinc oxide $(\mathrm{ZnO})$ from supercritical antisolvent (SAS) zinc acetate (ZnAc) nanoparticles calcined at $300,400,500$, and $600{ }^{\circ} \mathrm{C}$. 


\section{Materials and Methods}

\subsection{Materials}

Zinc acetate (ZnAc, purity $\geq 99 \%$ ) and crystal violet (CV, purity $\geq 90 \%$ ) were supplied by Sigma Aldrich (St. Louis, MO, USA). Dimethylsulfoxide (DMSO, purity 99.8\%) was purchased from Carlo Erba (Milan, Italy). $\mathrm{CO}_{2}$ (purity 99\%) was supplied by Morlando Group s.r.l. (Naples, Italy).

\subsection{Micronization of ZnAc by SAS Technique and Preparation of ZnO Photocatalysts}

ZnAc nanoparticles were produced by means of the SAS process. The homemade laboratory plant is sketched in Figure 9. The heart of the process is the precipitation chamber (PC), a cylindrical vessel with an internal volume equal to $500 \mathrm{~cm}^{3}$. Two high-pressure pumps P1 and P2 allow to feed, respectively, the $\mathrm{CO}_{2}$ (antisolvent) from the tank V1 and the liquid solution (DMSO $+\mathrm{ZnAc}$ ) contained in a burette (V2). In particular, the liquid solution is injected in the precipitation chamber through a stainless steel nozzle with an internal diameter of $100 \mu \mathrm{m}$. Instead, the $\mathrm{CO}_{2}$ is pre-cooled through a refrigerating bath (RB) and, after a preheating, it is delivered to the chamber. The pressure in the PC is measured by a test gauge manometer (M) and regulated by a micrometering valve (MV). The operating temperature inside the chamber is ensured by a proportional integral derivative (PID) controller connected with electrically thin bands. A stainless steel filter, characterized by pores with a diameter of $0.1 \mu \mathrm{m}$, is located at the bottom of the PC to collect the precipitated powders and to permit the $\mathrm{CO}_{2}$-solvent mixture to pass through. Then, the liquid solvent is recovered in a second collection vessel (LS), whose pressure (approximately 20 bar) is regulated by a backpressure valve (BPV). The flow rate of $\mathrm{CO}_{2}$ and its total quantity delivered are measured by a rotameter (R) and a dry test meter, respectively.

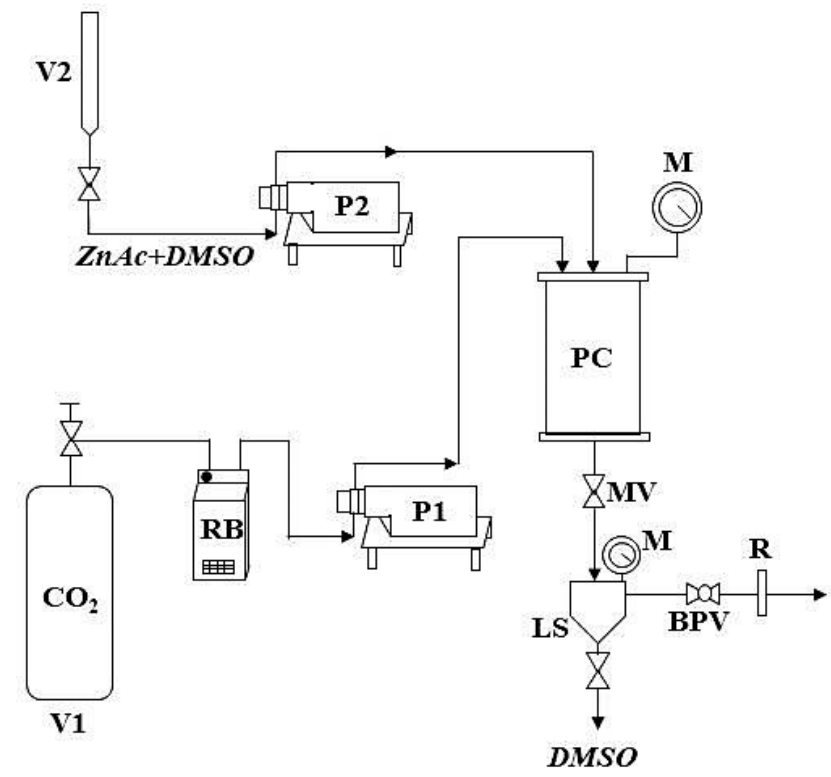

Figure 9. Schematic representation of supercritical antisolvent (SAS) apparatus. V1 is tank, V2 is burette, $\mathrm{RB}$ is refrigerating bath, $\mathrm{P} 1$ and $\mathrm{P} 2$ are pumps, $\mathrm{PC}$ is precipitation chamber, $\mathrm{M}$ is test gauge manometer, $\mathrm{MV}$ is micrometering valve, $\mathrm{LS}$ is collection vessel, BPV is backpressure valve, $\mathrm{R}$ is rotameter.

A typical SAS experiment begins by sending the $\mathrm{CO}_{2}$ to the precipitation chamber until the desired pressure and temperature are reached. After, pure solvent (DMSO) is injected through the nozzle up until a quasi-steady state composition of solvent and antisolvent is achieved within the chamber. Finally, the liquid solution, containing the solute to be micronized, is fed through the nozzle, leading to the precipitation of the solute. At the end of the solution injection, $\mathrm{CO}_{2}$ continues to flow to completely remove the solvent residues. After this washing step, the $\mathrm{CO}_{2}$ pumping is stopped, and the 
precipitation chamber is slowly depressurized up to the atmospheric pressure. Thus, the precipitated powders are collected and characterized.

In order to obtain zinc oxide, ZnAc precursor prepared through SAS micronization was calcined in a muffle furnace at different temperatures (i.e., at $300,400,500$, and $600^{\circ} \mathrm{C}$ ) to study the effect of different calcination conditions. In all cases, $\mathrm{ZnAc}$ was calcined for $2 \mathrm{~h}$ in air with a heating rate equal to $2{ }^{\circ} \mathrm{C} \times \mathrm{min}^{-1}$. Moreover, a comparison with a zinc oxide prepared by the calcination at $500{ }^{\circ} \mathrm{C}$ of unprocessed $\mathrm{ZnAc}$ (ZnOac500) was also performed to evaluate the effectiveness of the SAS technique in the production of $\mathrm{ZnO}$ photocatalyst.

\subsection{Photocatalytic Tests}

The photocatalytic tests were conducted in a cylindrical pyrex photoreactor (ID $=2.6 \mathrm{~cm}, \mathrm{~L}_{\mathrm{TOT}}=$ $41 \mathrm{~cm}$, and $\mathrm{V}_{\mathrm{TOT}}=200 \mathrm{~mL}$, Microglass Heim Srl, Naples, Italy). The photoreactor was equipped with an air distributor device $\left(Q_{\text {air }}=150 \mathrm{~cm}^{3} \times \mathrm{min}^{-1}\right)$ and a peristaltic pump (Watson Marlow, Falmouth, United Kingdom) to maintain continuous recirculation of the suspension inside the reactor. A UV-LEDs strip (nominal power: $12 \mathrm{~W}$, provided by LEDlightinghut (Shenzhen, China) emitting at $365 \mathrm{~nm}$ ) was positioned around and in contact with the external body of the photoreactor in order to irradiate the volume of the solution uniformly. The initial CV concentration was $10 \mathrm{mg} \times \mathrm{L}^{-1}$ while the solution volume, at the spontaneous $\mathrm{pH}$ (about 5.5), was $100 \mathrm{~mL}$. A catalyst amount of $0.15 \mathrm{~g}$ was employed for the tests.

Before the irradiation, the suspension was left in dark conditions for $240 \mathrm{~min}$ to provide the adsorption/desorption equilibrium on the photocatalyst surface and, after this step, the photocatalytic test was begun by switching on the LEDs, and the overall irradiation time was $180 \mathrm{~min}$. At fixed run time, almost $2 \mathrm{~mL}$ of liquid samples were withdrawn from the photoreactor and the residual CV concentration was analyzed through a UV-Vis spectrophotometer (Thermo Evolution 201, Thermo Fisher Scientific, Waltham, MA, USA) at the wavelength of $583 \mathrm{~nm}$ [3]. The total organic carbon (TOC) of the solutions as a function of irradiation time was measured by the high temperature combustion method described in our previous work [62].

\subsection{Chemical-Physical Characterization Methods}

A field emission scanning electron microscope (FESEM, mod. LEO 1525, Carl Zeiss SMT AG, Oberkochen, Germany) was used to observe the morphology of powders that were previously dispersed on a carbon tab stuck to an aluminum stub (Agar Scientific, Stansted, United Kingdom) and then coated with gold-palladium (layer thickness $250 \AA$ A) using a sputter coater (mod. 108 A, Agar Scientific). Considering approximately 1000 particles, mean diameter and standard deviation of particles were measured from FESEM images using the Sigma Scan Pro image analysis software (v5.0, Aspire Software International, Ashburn, VA, USA).

Fourier transform infrared (FT-IR) spectra were obtained via M2000 FT-IR (MIDAC Co, Costa Mesa, CA, USA), at a resolution of $0.5 \mathrm{~cm}^{-1}$. The scan wavenumber range was $4000-450 \mathrm{~cm}^{-1}$, and $16 \mathrm{scan}$ signals were averaged to reduce the noise. Powder samples were well mixed with potassium bromide $(\mathrm{KBr})$, which was used as the infrared transparent matrix. The discs, containing about $1 \mathrm{mg}$ of sample and $100 \mathrm{mg}$ of $\mathrm{KBr}$, were prepared by compressing the powders through a hydraulic press. Laser Raman spectra were obtained at room temperature with a Dispersive MicroRaman (Invia, Renishaw, Wotton-under-Edge, United Kingdom), equipped with $514 \mathrm{~nm}$ laser, in the range of $100-2000 \mathrm{~cm}^{-1}$ Raman shift. The ultraviolet-visible diffuse reflectance spectra (UV-Vis DRS) of the samples were recorded using a Perkin Elmer spectrometer Lambda 35 spectrophotometer (Waltham, MA, USA) using an RSA-PE-20 reflectance spectroscopy accessory (Labsphere Inc., North Sutton, NH, USA). The band gap values of the samples were determined through the corresponding Kubelka-Munk function $(K M)$ (which is proportional to the absorption of radiation) and by plotting $\left(K M \times h \times v^{2}\right)$ against $h \times v$. The Brunauer, Emmett, and Teller (BET) surface area of the samples was measured from dynamic $\mathrm{N}_{2}$ adsorption measurement at $-196^{\circ} \mathrm{C}$, performed by a Costech Sorptometer 1042 (Costech International 
S.p.A., Milan, Italy) after pre-treatment for $30 \mathrm{~min}$ in He flow at room temperature for the unprocessed and SAS processed $\mathrm{ZnAC}$ and at $150^{\circ} \mathrm{C}$ for all the calcined samples.

\section{Conclusions}

This work studied the synthesis of $\mathrm{ZnO}$ photocatalyst from thermal decomposition of zinc acetate (ZnAc) nanoparticles obtained by the supercritical antisolvent (SAS) precipitation method under different calcination conditions (in the range $300-600{ }^{\circ} \mathrm{C}$ ). The prepared photocatalysts were tested in the photocatalytic removal of crystal violet dye (CV) under UV irradiation. It was observed that the SAS technique was able to produce $\mathrm{ZnAc}$ in a regular nanometric structure (with a mean diameter of about $54.5 \pm 11.5 \mathrm{~nm}$ ) having a surface area of $20 \mathrm{~m}^{2} \times \mathrm{g}^{-1}$, whereas unprocessed ZnAc was characterized by very large crystals, whose specific surface area (SSA) was significantly lower and equal to $3 \mathrm{~m}^{2} \times \mathrm{g}^{-1}$. These differences influenced the properties of $\mathrm{ZnO}$ obtained after the thermal treatment of SAS ZnAc and unprocessed ZnAc particles. In fact, morphological analysis showed that the $\mathrm{ZnO}$ samples synthetized by thermal treatment at $500{ }^{\circ} \mathrm{C}$ of SAS ZnAc were characterized by a lower particle size (mean diameter: $65.0 \pm 14.5 \mathrm{~nm}$ ) and a higher SSA $\left(12 \mathrm{~m}^{2} \times \mathrm{g}^{-1}\right)$ with respect to the sample obtained by thermal treatment of unprocessed ZnAc particles, which showed a morphology characterized by irregular tetrapods with mean size equal to $181.1 \pm 65.5 \mathrm{~nm}$ and SSA equal to $5 \mathrm{~m}^{2} \times \mathrm{g}^{-1}$. Moreover, spectroscopic studies showed that organic impurities totally disappeared for the sample calcined at $500{ }^{\circ} \mathrm{C}$ (ZnOsas500 sample). These features could explain the superior photocatalytic performances (complete $\mathrm{CV}$ decolorization in $60 \mathrm{~min}$ of UV irradiation time and a mineralization degree higher than $90 \%$ after 120 min of treatment time) of the ZnOsas500 sample with respect to the $\mathrm{ZnO}$ obtained from unprocessed $\mathrm{ZnAc}$ particles and with respect to the samples obtained at 300 and $400{ }^{\circ} \mathrm{C}$ calcination temperature. Finally, a higher calcination temperature $\left(600^{\circ} \mathrm{C}\right)$ induced a worsening of the photocatalytic performances due to the decrease of SSA and the increase of particle size with respect to $\mathrm{ZnOsas500.}$

Author Contributions: O.S. and P.F. performed the experiments and wrote the manuscript. V.V. and I.D.M. provided the concept, experimental design of the study and reviewed the paper prior to submission. All authors discussed the results, analyzed the data, commented on and revised the manuscript.

Funding: This research received no external funding.

Conflicts of Interest: The authors declare no conflict of interest.

\section{References}

1. Nagaveni, K.; Sivalingam, G.; Hegde, M.S.; Madras, G. Solar photocatalytic degradation of dyes: High activity of combustion synthesized nano $\mathrm{TiO}_{2}$. Appl. Catal. B 2004, 48, 83-93. [CrossRef]

2. Vacchi, F.I.; de Souza Vendemiatti, J.A.; da Silva, B.F.; Zanoni, M.V.B.; Umbuzeiro, G.d.A. Quantifying the contribution of dyes to the mutagenicity of waters under the influence of textile activities. Sci. Total Environ. 2017, 601-602, 230-236. [CrossRef]

3. Sacco, O.; Matarangolo, M.; Vaiano, V.; Libralato, G.; Guida, M.; Lofrano, G.; Carotenuto, M. Crystal violet and toxicity removal by adsorption and simultaneous photocatalysis in a continuous flow micro-reactor. Sci. Total Environ. 2018, 644, 430-438. [PubMed]

4. Muhd Julkapli, N.; Bagheri, S.; Bee Abd Hamid, S. Recent advances in heterogeneous photocatalytic decolorization of synthetic dyes. Sci. World J. 2014, 2014, 692307. [CrossRef] [PubMed]

5. Ghaffar, A.; Zhang, L.; Zhu, X.; Chen, B. Porous pvdf/go nanofibrous membranes for selective separation and recycling of charged organic dyes from water. Environ. Sci. Technol. 2018, 52, 4265-4274. [CrossRef]

6. Pal, B.; Kaur, R.; Grover, I.S. Superior adsorption and photodegradation of eriochrome black-t dye by $\mathrm{Fe}^{3+}$ and $\mathrm{Pt}^{4+}$ impregnated $\mathrm{TiO}_{2}$ nanostructures of different shapes. J. Ind. Eng. Chem. 2016, 33, 178-184. [CrossRef]

7. Ong, S.-T.; Cheong, W.-S.; Hung, Y.-T. Photodegradation of commercial dye, methylene blue using immobilized $\mathrm{Ti}_{2}$. In Proceedings of the 4 th International Conference on Chemical, Biological and Environmental Engineering, Phuket, Thailand, 1-2 September 2012. 
8. Sacco, O.; Vaiano, V.; Han, C.; Sannino, D.; Dionysiou, D.D. Photocatalytic removal of atrazine using N-doped $\mathrm{TiO}_{2}$ supported on phosphors. Appl. Catal. B 2015, 164, 462-474. [CrossRef]

9. Liu, F.-Y.; Li, B.-H.; Xu, Y.-S. Overview on heterogeneous photocatalytic degradation of organic contaminants in wastewater on semiconductors. Guangzhou Huaxue 2001, 26, 44-51.

10. Sacco, O.; Vaiano, V.; Rizzo, L.; Sannino, D. Photocatalytic activity of a visible light active structured photocatalyst developed for municipal wastewater treatment. J. Cleaner Prod. 2018, 175, 38-49. [CrossRef]

11. Rajamanickam, D.; Shanthi, M. Photocatalytic degradation of an organic pollutant by zinc oxide-Solar process. Arabian J. Chem 2016, 9, S1858-S1868.

12. Akkari, M.; Aranda, P.; Belver, C.; Bedia, J.; Ben Haj Amara, A.; Ruiz-Hitzky, E. ZnO/sepiolite heterostructured materials for solar photocatalytic degradation of pharmaceuticals in wastewater. Appl. Clay Sci. 2018, 156, 104-109. [CrossRef]

13. Vaiano, V.; Matarangolo, M.; Sacco, O.; Sannino, D. Photocatalytic treatment of aqueous solutions at high dye concentration using praseodymium-doped ZnO catalysts. Appl. Catal. B 2017, 209, 621-630. [CrossRef]

14. Ong, C.B.; Ng, L.Y.; Mohammad, A.W. A review of zno nanoparticles as solar photocatalysts: Synthesis, mechanisms and applications. Renew. Sustain. Energy Rev. 2018, 81, 536-551. [CrossRef]

15. Vaiano, V.; Matarangolo, M.; Sacco, O. UV-LEDs floating-bed photoreactor for the removal of caffeine and paracetamol using ZnO supported on polystyrene pellets. Chem. Eng. J. 2018, 350, 703-713. [CrossRef]

16. Cataño, F.A.; Valencia, S.H.; Hincapié, E.A.; Restrepo, G.; Marín, J.M. A comparative study between $\mathrm{TiO}_{2}$ and $\mathrm{ZnO}$ photocatalysis: Photocatalytic degradation of cibacron yellow FN-2R dye. Lat. Am. Appl. Res. 2012, 42, 33-38.

17. Murcia Mesa, J.J.; Arias Bolivar, L.G.; Sarmiento, H.A.R.; Martínez, E.G.Á.; Páez, C.J.; Lara, M.A.; Santos, J.A.N.; del Carmen Hidalgo López, M. Urban wastewater treatment by using Ag/ZnO and Pt/TiO 2 photocatalysts. Environ. Sci. Pollut. Res. 2019, 26, 4171-4179. [CrossRef] [PubMed]

18. Jaramillo-Páez, C.; Navío, J.A.; Hidalgo, M.C.; Macías, M. High uv-photocatalytic activity of ZnO and $\mathrm{Ag} / \mathrm{ZnO}$ synthesized by a facile method. Catal. Today 2017, 284, 121-128. [CrossRef]

19. Chen, P.K.; Lee, G.J.; Davies, S.; Masten, S.; Amutha, R.; Wu, J. Hydrothermal synthesis of coral-like au/zno catalyst and photocatalytic degradation of orange ii dye. Mater. Res. Bull. 2013, 48, 2375-2382. [CrossRef]

20. Rokesh, K.; Jeganathan, K.; Jothivenkatachalam, K. Zinc oxide-palladium material an efficient solar-light driven photocatalyst for degradation of congo red. Nanosyst. Phys. Chem. Math. 2016, 7, 740-746. [CrossRef]

21. Vaiano, V.; Iervolino, G.; Rizzo, L. Cu-doped ZnO as efficient photocatalyst for the oxidation of arsenite to arsenate under visible light. Appl. Catal. B 2018, 238, 471-479. [CrossRef]

22. Vaiano, V.; Matarangolo, M.; Sacco, O.; Sannino, D. Photocatalytic removal of eriochrome blackT dye over ZnO nanoparticles doped with Pr, Ce or Eu. Chem. Eng. Trans. 2017, 57, 625-630.

23. Fan, J.; Zhao, L.; Yu, J.; Liu, G. The effect of calcination temperature on the microstructure and photocatalytic activity of $\mathrm{TiO}_{2}$-based composite nanotubes prepared by an in situ template dissolution method. Nanoscale 2012, 4, 6597-6603. [CrossRef] [PubMed]

24. Ul Haq, A.N.; Nadhman, A.; Ullah, I.; Mustafa, G.; Yasinzai, M.; Khan, I. Synthesis approaches of zinc oxide nanoparticles: The dilemma of ecotoxicity. J. Nanomater. 2017. [CrossRef]

25. Zhang, J.; Zhao, B.; Pan, Z.; Gu, M.; Punnoose, A. Synthesis of zno nanoparticles with controlled shapes, sizes, aggregations, and surface complex compounds for tuning or switching the photoluminescence. Cryst. Growth Des. 2015, 15, 3144-3149. [CrossRef]

26. Wojnarowicz, J.; Chudoba, T.; Malka, I.; Gierlotka, S.; Dworakowska, S.; Lojkowski, W. Size control mechanism of $\mathrm{ZnO}$ nanoparticles obtained in microwave solvothermal synthesis. Nanotechnology 2018, 29, 065601. [CrossRef] [PubMed]

27. Lee, W.; Leem, J.-Y. Size control of $\mathrm{ZnO}$ nanorods using the hydrothermal method in conjunction with substrate rotation. J. Nanosci. Nanotechnol. 2017, 17, 7952-7956. [CrossRef]

28. Kuriakose, S.; Satpati, B.; Mohapatra, S. Effects of solvent on structural, optical and photocatalytic properties of zno nanostructures. Adv. Mater. Lett. 2015, 6, 1104-1110. [CrossRef]

29. Xu, L.; Hu, Y.-L.; Pelligra, C.; Chen, C.-H.; Jin, L.; Huang, H.; Sithambaram, S.; Aindow, M.; Joesten, R.; Suib, S.L. ZnO with different morphologies synthesized by solvothermal methods for enhanced photocatalytic activity. Chem. Mater. 2009, 21, 2875-2885. [CrossRef] 
30. Talebian, N.; Amininezhad, S.M.; Doudi, M. Controllable synthesis of ZnO nanoparticles and their morphology-dependent antibacterial and optical properties. J. Photochem. Photobiol. B 2013, 120, 66-73. [CrossRef]

31. Belver, C.; Bedia, J.; Rodriguez, J.J. Zr-doped $\mathrm{TiO}_{2}$ supported on delaminated clay materials for solar photocatalytic treatment of emerging pollutants. J. Hazard. Mater. 2017, 322, 233-242. [CrossRef]

32. Franco, P.; Martino, M.; Palma, V.; Scarpellini, A.; De Marco, I. Pt on SAS-CeO 2 nanopowder as catalyst for the co-WGS reaction. Int. J. Hydrog. Energy 2018, 43, 19965-19975. [CrossRef]

33. Tang, Z.-R.; Edwards, J.K.; Bartley, J.K.; Taylor, S.H.; Carley, A.F.; Herzing, A.A.; Kiely, C.J.; Hutchings, G.J. Nanocrystalline cerium oxide produced by supercritical antisolvent precipitation as a support for high-activity gold catalysts. J. Catal. 2007, 249, 208-219. [CrossRef]

34. Marin, R.P.; Kondrat, S.A.; Davies, T.E.; Morgan, D.J.; Enache, D.I.; Combes, G.B.; Taylor, S.H.; Bartley, J.K.; Hutchings, G.J. Novel cobalt zinc oxide Fischer-Tropsch catalysts synthesised using supercritical anti-solvent precipitation. Catal. Sci. Technol. 2014, 4, 1970-1978. [CrossRef]

35. Franco, P.; Reverchon, E.; De Marco, I. Zein/diclofenac sodium coprecipitation at micrometric and nanometric range by supercritical antisolvent processing. J. $\mathrm{CO}_{2}$ Util. 2018, 27, 366-373. [CrossRef]

36. Reverchon, E.; De Marco, I.; Della Porta, G. Tailoring of nano- and micro-particles of some superconductor precursors by supercritical antisolvent precipitation. J. Supercrit. Fluids 2002, 23, 81-87. [CrossRef]

37. Marin, R.P.; Ishikawa, S.; Bahruji, H.; Shaw, G.; Kondrat, S.A.; Miedziak, P.J.; Morgan, D.J.; Taylor, S.H.; Bartley, J.K.; Edwards, J.K.; et al. Supercritical antisolvent precipitation of $\mathrm{TiO}_{2}$ with tailored anatase/rutile composition for applications in redox catalysis and photocatalysis. Appl. Catal. A 2015, 504, 62-73. [CrossRef]

38. Da Silva, E.P.; Winkler, M.E.G.; Giufrida, W.M.; Cardozo-Filho, L.; Alonso, C.G.; Lopes, J.B.O.; Rubira, A.F.; Silva, R. Effect of phase composition on the photocatalytic activity of titanium dioxide obtained from supercritical antisolvent. J. Colloid Interface Sci. 2019, 535, 245-254. [CrossRef]

39. Mani, S.; Bharagava, R.N. Exposure to crystal violet, its toxic, genotoxic and carcinogenic effects on environment and its degradation and detoxification for environmental safety. Rev. Environ. Contam. Toxicol. 2015, 237, 71-104.

40. Au, W.; Pathak, S.; Collie, C.J.; Hsu, T.C. Cytogenetic toxicity of gentian violet and crystal violet on mammalian cells in vitro. Mutat. Res. Genet. Toxicol. 1978, 58, 269-276. [CrossRef]

41. Reverchon, E.; Della Porta, G.; Sannino, D.; Ciambelli, P. Supercritical antisolvent precipitation of nanoparticles of a zinc oxide precursor. Powder Technol. 1999, 102, 127-134. [CrossRef]

42. Handoko, A.D.; Liew, L.-L.; Lin, M.; Sankar, G.; Du, Y.; Su, H.; Dong, Z.; Goh, G.K.L. Elucidation of thermally induced internal porosity in zinc oxide nanorods. Nano Res. 2018, 11, 2412-2423. [CrossRef]

43. Vu, T.T.; Valdés-Solís, T.; Marbán, G. High surface area stainless steel wire mesh-supported $\mathrm{TiO}_{2}$ prepared by sacrificial template accelerated hydrolysis. A monolithic photocatalyst superior to $\mathrm{P} 25 \mathrm{TiO}_{2}$. J. Environ. Chem. Eng. 2014, 2, 2229-2235. [CrossRef]

44. Kołodziejczak-Radzimska, A.; Markiewicz, E.; Jesionowski, T. Structural characterisation of ZnO particles obtained by the emulsion precipitation method. J. Nanomater. 2012, 2012. [CrossRef]

45. Faisal, M.; Ismail, A.A.; Ibrahim, A.A.; Bouzid, H.; Al-Sayari, S.A. Highly efficient photocatalyst based on Ce doped $\mathrm{ZnO}$ nanorods: Controllable synthesis and enhanced photocatalytic activity. Chem. Eng. J. 2013, 229, 225-233. [CrossRef]

46. Li, C.; Lv, Y.; Guo, L.; Xu, H.; Ai, X.; Zhang, J. Raman and excitonic photoluminescence characterizations of ZnO star-shaped nanocrystals. J. Lumin. 2007, 122-123, 415-417. [CrossRef]

47. Yang, M.M.; Crerar, D.A.; Irish, D.E. A raman spectroscopic study of lead and zinc acetate complexes in hydrothermal solutions. Geochim. Cosmochim. Acta 1989, 53, 319-326. [CrossRef]

48. Baruwati, B.; Kumar, D.K.; Manorama, S.V. Hydrothermal synthesis of highly crystalline ZnO nanoparticles: A competitive sensor for lpg and etoh. Sens. Actuators B 2006, 119, 676-682. [CrossRef]

49. Anpo, M.; Shima, T.; Kodama, S.; Kubokawa, Y. Photocatalytic hydrogenation of propyne with water on small-particle titania: Size quantization effects and reaction intermediates. J. Phys. Chem. 1987, 91, 4305-4310. [CrossRef]

50. Kormann, C.; Bahnemann, D.W.; Hoffmann, M.R. Preparation and characterization of quantum-size titanium dioxide. J. Phys. Chem. 1988, 92, 5196-5201. [CrossRef]

51. Busuioc, C.; Evanghelidis, A.; Enculescu, M.; Enculescu, I. Optical and photocatalytic properties of electrospun ZnO fibers. Dig. J. Nanomater. Biostruct. 2015, 10, 957-965. 
52. Preda, N.; Enculescu, M.; Enculescu, I. Polysaccharide-assisted crystallization of ZnO micro/nanostructures. Mater. Lett. 2014, 115, 256-260. [CrossRef]

53. Jiménez Reinosa, J.; Leret, P.; Álvarez-Docio, C.M.; del Campo, A.; Fernández, J.F. Enhancement of UV absorption behavior in $\mathrm{ZnO}-\mathrm{TiO}_{2}$ composites. Boletín de la Sociedad Española de Cerámica y Vidrio 2016, 55, 55-62. [CrossRef]

54. Wang, K.-H.; Hsieh, Y.-H.; Lin, T.-T.; Chang, C.-Y. Effects of temperature on the properties of $\mathrm{TiO}_{2}$ photocatalysts prepared by the chemical vapor deposition (CVD) method. React. Kinet. Catal. Lett. 2008, 95, 39-46. [CrossRef]

55. Jang, H.D.; Kim, S.-K.; Kim, S.-J. Effect of particle size and phase composition of titanium dioxide nanoparticles on the photocatalytic properties. J. Nanopart. Res. 2001, 3, 141-147. [CrossRef]

56. Sheikhnejad, O.; Feng, Z.; Rajabtabar, A.; Khodadad, E.; Yudong Huang, A. Precursor and reaction time effects in evaluation of photocatalytic properties of $\mathrm{TiO}_{2}$ nanoparticles synthesized via low temperature. Int. J. Electrochem. Sci. 2014, 9, 3068-3077.

57. Flores, N.M.; Pal, U.; Galeazzi, R.; Sandoval, A. Effects of morphology, surface area, and defect content on the photocatalytic dye degradation performance of ZnO nanostructures. RSC Adv. 2014, 4, 41099-41110. [CrossRef]

58. Giraldi, T.; Fonseca Santos, G.; De Mendonça, V.; Ribeiro, C.; Weber, I. Annealing effects on the photocatalytic activity of ZnO nanoparticles. J. Nanosci. Nanotechnol. 2011, 11, 3635-3640. [CrossRef]

59. Rao, P.; Patel, G.; Sharma, S.L.; Ameta, S.C. Photocatalytic degradation of crystal violet over semiconductor zinc oxide powder suspended in aqueous solution. Toxicol. Environ. Chem. 1997, 60, 155-161. [CrossRef]

60. Ameen, S.; Akhtar, M.S.; Nazim, M.; Shin, H.-S. Rapid photocatalytic degradation of crystal violet dye over zno flower nanomaterials. Mater. Lett. 2013, 96, 228-232. [CrossRef]

61. Sacco, O.; Vaiano, V.; Sannino, D.; Ciambelli, P. Visible light driven mineralization of spiramycin over photostructured N-doped $\mathrm{TiO}_{2}$ on up conversion phosphors. J. Environ. Sci. 2017, 54, 268-276. [CrossRef]

62. Sacco, O.; Sannino, D.; Vaiano, V. Packed bed photoreactor for the removal of water pollutants using visible light emitting diodes. App. Sci. 2019, 9, 472. [CrossRef]

(C) 2019 by the authors. Licensee MDPI, Basel, Switzerland. This article is an open access article distributed under the terms and conditions of the Creative Commons Attribution (CC BY) license (http://creativecommons.org/licenses/by/4.0/). 